suppression of shoot growth is in itself an undesirable effect, and in these trees may cause a lowered flower production both in 1946 and 1947 .

Since this trial was initiated, other substances have been brought to my notice, and these may be even more effective on apples and pears than the ones used above. Furthermore, the success obtained with tomato flower extract and animal sex hormones as recently reported by $\mathrm{me}^{2}$ offers still further scope for development along these lines.

Research Station,

(University of Bristol),

Long Ashton, Bristol.

Oct. 9.

${ }^{1}$ Swarbrick, T., Rep. Agric. Hort. Res. Station, Bristol, for 1944, 36 (1945).

${ }^{2}$ Swarbrick, T., Nature, 156, 300 (1945).

\section{Accumulation of Sugars in Barley Seedlings on Very Acid Soil}

For a number of years it has been noticed at Woburn that seedling barley plants sown in soil too acid to allow normal growth $(p \mathrm{H} 4 \cdot 3$ or thereabouts) were very much more attractive to small birds (chaffinches and the like) than similar seedlings grown on a normal soil $(p \mathrm{H} 6 \cdot 0-6 \cdot 5)$; and that consequently a very large proportion of the growing seedlings wore dug up and the seeds eaten when little or no similar damage was done to plants on normal soil. At first the tendency was to attribute the difference to the slowness of growth on the acid soil, which kept the seodlings in a condition suitable for bird attack for a much longer poriod, but this explanation failed when it was found that the seedlings were attacked almost as soon as the shoots appeared above the ground.

It seemed certain that the seedlings on the very acid soil contained something which made them more attractive to birds, and it was suggested that there might be an accumulation of sugars which made them much sweeter than normal plants at the same stage of growth. We have now examined on several occasions seedlings from both types of soil, grown on trays under similar conditions to the point when the second leaf was just visible, when they are still quite attractive to birds. This stage was reached with normal soil in 11-15 days, and with the very acid soil in 19-21 days. The plants were then pulled up in the morning, the fibrous roots cut off, the seeds and the tops separated from one another and the total sugars soluble in alcohol determined with Fehling's solution after inversion with acid.

The results obtained in two separate experiments are shown below, the percentages being on the dry matter of the tops or the seeds.

\begin{tabular}{|c|c|c|c|c|}
\hline & \multicolumn{4}{|c|}{ GLUCOSE EQUIVALENT OF TOTAL SUGARS } \\
\hline & Normal soi & $(p$ H $6 \cdot 5)$ & Very acid & il $(p \mathrm{H} 4 \cdot 2)$ \\
\hline & $\begin{array}{l}\text { Tops } \\
5 \cdot 3 \text { per cent }\end{array}$ & $\begin{array}{l}\text { Seeds } \\
26.8 \text { per cent }\end{array}$ & $\begin{array}{l}\text { Tops } \\
24 \cdot 1 \text { per cent }\end{array}$ & $\begin{array}{ll} & \text { Seeds } \\
42 \cdot 6 & \text { per cent }\end{array}$ \\
\hline & 4 & $21 \cdot 1$ & , & $30 \cdot 6$ \\
\hline
\end{tabular}

It is clear, therefore, that there tends to be an accumulation of sugar both in the tops and in the seeds where the seedlings are grown on very acid soil, probably due to the feeble growth of the seedlings after germination has taken place.

The cause of the attractiveness to the birds is still better shown if the figures are given as sugar (that is, glucose equivalent) per 100 tops or seeds. These are as follows :
GLUCOSE EQUIVALENT OF TOTAL SUgARS PHR 100 TOPS OR SEEDS

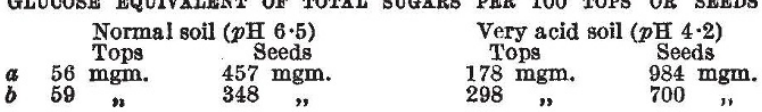

T. W. BARNES.

Woburn Experimental Station, Husborne Crawley, Bletchley.

Aug. 15.

\section{Acoustic Control in the Flight of Bats}

Prof. Hartridge has suggested ${ }^{1}$ a comparison between radar and acoustic range- and directionfinding in bats. He suggests that the interrupted supersonic note may be used to measure the range to obstacles. The note emitted lasts about 0.01 sec. During this time the first waves of the sound will travel about $10 \mathrm{ft}$. To determine range with any accuracy either the onset (leading edge) or the ending (trailing edge) of the echo must be used as a point of reference.

If it is assumed that a bat, like a radar set, uses the leading edge of the echo to judge range, the least range which it could perceive would be considerable. In a radar equipment with a $1 \mu$ sec. pulse the leading edge of the echo from an object at less than 150 metres from the aerials will be received during the period of transmission and therefore lost. For a bat there will be a similar range blind to the leading edge of about $5 \mathrm{ft}$. It is possible that the bat uses the trailing edge of the echo, however. In these circumstances there will be no well-defined lower limit of range measurement. One function of the complex intra-aural muscle reflex may be to make use of the trailing edge, for without this the reflected note from close objects would appear to the bat as con. tinuous with the emitted one. In natural conditions the eyes no doubt also assist in perceiving near objects.

The maximum range at which an object can be detected may also be limited. In an airborne radar equipment which is so designed that the outgoing signals are not beamed, the maximum range at which an aircraft can be detected is equal to the height of the radar equipment. This is because the signals reflected from the ground tend to swamp all others. It is possible that the bat overcomes this difficulty by the great development of the pinnæe of the ears, which may allow it to hear only echoes from objects directly ahead.

Great Missenden,

D. W. EWER.

Bucks.

Nov. 4.

${ }^{1}$ Hartridge, H., Nature, 156, 490 (1945).

Dr. Ewer has raised an interesting point with regard to bats' hearing which I have been trying to elucidate. We have been approaching the matter from somewhat different points of view. There is very strong evidence that bats are aware of obstacles ahead of them not only when they are several metres away, but also when they are quite close. Thus during my experiments in King's College in 1919, these animals were observed to fly quickly through an open doorway from one room to another. "If the intervening door was gradually closed to six 